\title{
Ulnar Nerve
}

National Cancer Institute

\section{Source}

National Cancer Institute. Ulnar Nerve. NCI Thesaurus. Code C52807.

A major peripheral nerve of the upper limb; it originates as the medial cord of the brachial plexus, and contains fibers from the C8-T1 nerve roots. It functions to supply both sensory and motor innervation to parts of the forearm and hand. 